The influence of $\operatorname{SiN}_{x}: \mathrm{H}$ film properties on the electrical characteristics of metal - insulator semiconductor devices

This content has been downloaded from IOPscience. Please scroll down to see the full text. 1997 Semicond. Sci. Technol. 121650

(http://iopscience.iop.org/0268-1242/12/12/018)

View the table of contents for this issue, or go to the journal homepage for more

Download details:

IP Address: 147.96.14.15

This content was downloaded on 14/02/2014 at 18:14

Please note that terms and conditions apply. 


\title{
The influence of $\mathrm{SiN}_{x}: \mathrm{H}$ film properties on the electrical characteristics of metal-insulator-semiconductor devices
}

\author{
S Garcia $\nmid$, I Mártil $\dagger \dagger$, G Gonzalez Diaz $\dagger$ and M Fernandez $\S$ \\ $\dagger$ Dpto. Fisica Aplicada III, Fac. Fisicas, Univ. Complutense, 28040 Madrid, Spain \\ $\S$ Instituto de Ciencia de Materiales, Cantoblanco, 28049 Madrid, Spain
}

Received 10 June 1997, accepted for publication 9 September 1997

\begin{abstract}
SiN}_{x}: \mathrm{H}$ thin films were deposited by the electron cyclotron resonance plasma method at low substrate temperature $\left(200^{\circ} \mathrm{C}\right)$ to fabricate metal-insulator-semiconductor devices. The effects of film properties on the electrical characteristics of two different devices, $\mathrm{SiN}_{x}: \mathrm{H} / \mathrm{Si}$ and $\mathrm{SiN}_{x}: \mathrm{H} / \mathrm{InP}$, were analysed according to the $C-V$ high-low frequency method. The results show that, in the devices based on $\mathrm{Si}$, the presence of $\mathrm{N}-\mathrm{H}$ bonds in the $\mathrm{SiN}_{x}: \mathrm{H}$ film increases the density of trapping centres at the insulator/semiconductor interface. This behaviour was analysed by the model recently proposed by Ying (1995 J. Vac. Sci. Technol. B 13 1613) for nitrided $\mathrm{SiO}_{2} / \mathrm{Si}$ interfaces. For the $\mathrm{SiN}_{x}: \mathrm{H} / \mathrm{InP}$ capacitors, the electrical characteristics of the interface were strongly dependent on the $\mathrm{SiN}_{x}: \mathrm{H}$ composition. When the nitrogen to silicon ratio of the film was $\mathrm{N} / \mathrm{Si}=1.49$, the minimum of the interface trap density was $2 \times 10^{12} \mathrm{~cm}^{-2} \mathrm{eV}^{-1}$. This value was similar to the same data reported by other authors on devices where the InP surface was sulphur passivated. This suggests that nitrogen atoms of the insulator play some passivation role at the InP surface. The plasma exposure of the semiconductor surface during the deposition of the $\mathrm{SiN}_{x}: \mathrm{H}$ film promotes the formation of phosphorus vacancies at the InP surface. Nitrogen atoms may fill these vacancies and this gives rise to an insulator/semiconductor interface with few defects.
\end{abstract}

\section{Introduction}

Thin films of $\operatorname{SiN}_{x}: \mathrm{H}$ deposited by the electron cyclotron resonance plasma method (ECR) at low temperatures $\left(200^{\circ} \mathrm{C}\right.$ or below) have shown excellent insulator properties: high density [1], low hydrogen content [2], high resistivity and high breakdown field [3]. This means that the films can be used as gate insulators on metal-insulatorsemiconductor devices (MIS). $\mathrm{SiN}_{x}: \mathrm{H}$ films deposited by ECR have been successfully used on MIS structures with different semiconductors such as GaAs [3], InP [4] and $\mathrm{Si}$ [5]. At present, for devices based on III-V semiconductors it is necessary to use techniques of passivation of the semiconductor surface to obtain an insulator/semiconductor interface with a low density of interface traps. Values as low as $8 \times 10^{10} \mathrm{~cm}^{-2} \mathrm{eV}^{-1}$ for devices with GaAs [3], and $3 \times 10^{12} \mathrm{~cm}^{-2} \mathrm{eV}^{-1}$ with InP [4], have been reported recently.

$\ddagger$ E-mail address: imartil@eucmax.sim.ucm.es
Even though the use of these passivation procedures seems to be mandatory to obtain devices of good quality, this does not allow us to determine the influence of the insulator properties on the characteristics of the interface, since when passivation layers are present, the electrical characteristics of the interface become almost independent of the insulator characteristics. As a consequence, in surface passivated devices the main influence on the interface behaviour is related to the procedure followed to passivate the semiconductor surface [3]. Hence, the characteristics of the insulator play a secondary role on the electrical properties of the device. To know the role of the insulator properties on the electrical characteristics of the MIS devices, it is necessary to avoid the surface passivation step, i.e. the insulator should be deposited directly on top of the semiconductor surface.

In this paper we present an analysis of the influence of the properties of $\mathrm{SiN}_{x}: \mathrm{H}$ thin films, deposited by the ECR plasma method, on the electrical characteristics of MIS structures made with two different semiconductors: 
$\mathrm{Si}$ and InP. According to the previous paragraph, we do not use any intentional procedure of passivation for the semiconductor surface. Analysis of the electrical characteristics of devices without surface passivation has recently been reported as a means of knowing the damage induced at the surface by different plasma techniques on semiconductors like InP [6] and InGaAs [7]. Due to the fact that the ECR plasma technique is a 'soft' process, the damage induced at the semiconductor surface during the insulator deposition is expected to be minimal. Consequently, the electrical characteristics of the two different interfaces we have analysed, namely $\mathrm{SiN}_{x}: \mathrm{H} / \mathrm{Si}$ and $\mathrm{SiN}_{x}: \mathrm{H} / \mathrm{InP}$, are expected to be determined not only by the semiconductor surface but mainly by the physical properties of the insulator. We will show that through careful control of the insulator deposition conditions, the ECR plasma method enables us to obtain devices with low values of the interface trap density for the two different structures subject to analysis.

\section{Experimental}

$\mathrm{SiN}_{x}: \mathrm{H}$ thin films were deposited in a vacuum chamber of our design attached to an Astex 4500 ECR reactor. Microwave power $(2.45 \mathrm{GHz}, 100 \mathrm{~W})$, gas discharge pressure $\left(0.6\right.$ mTorr) and deposition temperature $\left(200^{\circ} \mathrm{C}\right)$ were kept constant in all the experiments. The gas flux ratio $R=\mathrm{N}_{2} / \mathrm{SiH}_{4}$ was modified between $R=1.6$ and $R=9$ to obtain $\mathrm{SiN}_{x}: \mathrm{H}$ films of variable composition. This composition was measured by Auger electron spectroscopy to obtain the nitrogen to silicon ratio of the films. We shall refer to that as $x$ from now onwards. In a previous study [2], we have shown that using the range for $R$ indicated, we can obtain films with compositions between $x=0.91$ (at $R=1.6$ ) and $x=1.49$ (at $R=9$ ). When using higher values of $R$, we obtained films where the parameter $x$ was always $1.5 \pm 0.05$. Following the procedure described in [8] we also determine the bonding characteristics of the films and their hydrogen content using infrared absorption measurements.

The MIS capacitors were obtained as follows: the devices based on $\mathrm{Si}$ were fabricated using n-type wafers ( $5 \Omega \mathrm{cm},\langle 100\rangle$ orientation). Prior to the deposition of the $\mathrm{SiN}_{x}: \mathrm{H}$, the Si substrate was degreased in organic solvents and an $\mathrm{Al}$ back electrode (3000 $\AA$ thick) was thermally evaporated and alloyed at $480^{\circ} \mathrm{C}$ for $3 \mathrm{~min}$ in Ar. After this step, a standard chemical procedure was carried out in order to clean the $\mathrm{Si}$ : etched in a $\mathrm{HF}: \mathrm{H}_{2} \mathrm{O}(1: 10)$ solution for $15 \mathrm{~s}$, then rinsed in deionized water and blown dry in $\mathrm{N}_{2}$. Throughout the cleaning, the back electrode was protected with resist.

In the devices based on InP, we used also n-type wafers, nominally undoped $\left(4 \times 10^{15} \mathrm{~cm}^{-3},\langle 100\rangle\right.$ orientation). As in the case of the Si based devices, after degreasing the back electrode was thermally evaporated. This was a bilayer $\mathrm{AuGe} / \mathrm{Au}, 1500 / 1000 \AA$ thick, alloyed at $350{ }^{\circ} \mathrm{C}$ for $2 \mathrm{~min}$ in Ar. Then the InP wafers were etched in $10 \mathrm{wt} \%$ $\mathrm{H}_{2} \mathrm{IO}_{3}: \mathrm{H}_{2} \mathrm{O}$ for $60 \mathrm{~s}$, rinsed in deionized water, etched in $\mathrm{HF}: \mathrm{H}_{2} \mathrm{O}(1: 10)$ for $15 \mathrm{~s}$, rinsed in deionized water once more and blown dry in $\mathrm{N}_{2}$.

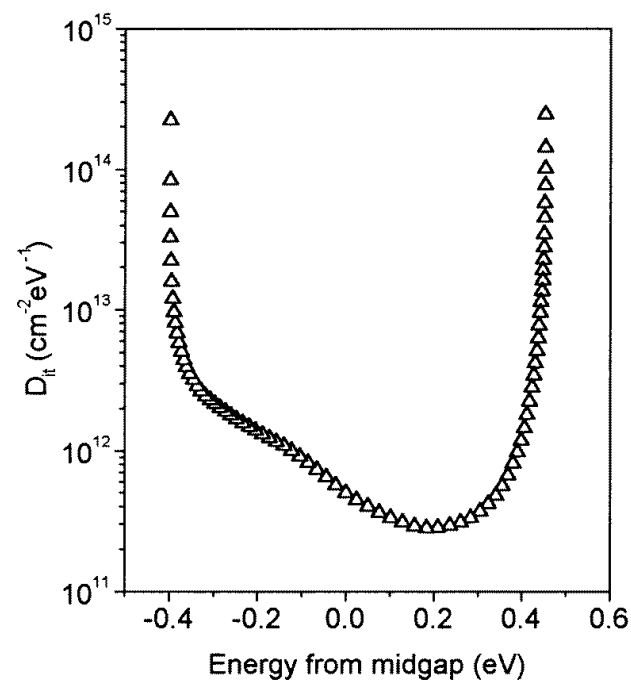

Figure 1. Distribution of interface trap density versus energy plotted relative to the midgap, for the $\mathrm{SiN}_{x}: \mathrm{H} / \mathrm{Si}$ device. Results are for optimum deposition conditions of the insulator.

Both substrates were introduced into the deposition chamber immediately after the cleaning, and the insulator was then deposited (500 $\AA$ thick). As a final step, in both structures an $\mathrm{Al}$ top electrode was thermally evaporated through a mask to define $1.2 \times 10^{-3} \mathrm{~cm}^{2}$ square electrodes. Post-metallization annealing was accomplished in an $\mathrm{Ar}$ atmosphere $\left(300^{\circ} \mathrm{C}, 20 \mathrm{~min}\right)$. The electrical characterization of the capacitors was done by measuring the $C-V$ quasistatic and high frequency curves with a Keithley model 82 system. The interface trap density was obtained using the high-low frequency method [9].

\section{Results and discussion}

In figure 1, we present the distribution of the interface trap density $\left(D_{i t}\right)$ within the forbidden gap for an $\mathrm{Si}$ based device. The distribution was obtained with the insulator deposited at a gas flux ratio $R=5$, which gave the best interface characteristics. We obtained similar characteristics to that shown in figure 1 when the values of $R$ were between 1.5 and 5. In this range, $x$ changes from $x=0.91(R=1.5)$ to $x=1.38(R=5)$. The minimum of the trap density appears in all the devices at $0.15 \mathrm{eV}$ above the midgap, and the range of energies where the trap distribution remains low was wide. This means that the interface is good, without Fermi level pinning. Similar results have recently been reported for $\mathrm{SiN}_{x}: \mathrm{H}$ films deposited by distributed ECR [5].

In figure 2 we present the minimum of $D_{i t}$ as a function of the film composition, $x$, for the $\mathrm{SiN}_{x}: \mathrm{H} / \mathrm{Si}$ structures. We also present the same results obtained for the $\mathrm{SiN}_{x}: \mathrm{H} / \mathrm{InP}$ capacitors, which will be analysed later. It is worth noting that the plasma damage induced at the semiconductor surface was similar in all the devices, since the microwave power and the total pressure used to deposit the insulator were kept constant. As a consequence, differences between capacitors should be 


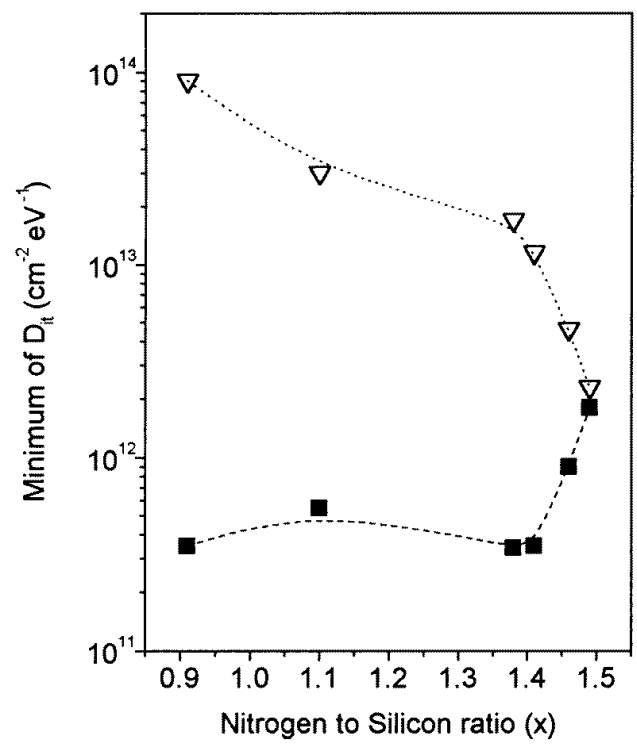

Figure 2. Minimum of the trap density, $D_{i t}$, as a function of the N/Si ratio of the $\mathrm{SiN}_{x}: \mathrm{H}$ films, for $\mathrm{SiN}_{x}: \mathrm{H} / \mathrm{Si}(\boldsymbol{\square})$ and $\mathrm{SiN}_{x}: \mathrm{H} / \operatorname{InP}(\nabla)$. Curves are drawn as a guide for the eye.

mainly related to differences in $\mathrm{SiN}_{x}: \mathrm{H}$ film properties. The results of figure 2 for the $\mathrm{SiN}_{x}: \mathrm{H} / \mathrm{Si}$ structures showed a range of film compositions $(0.9<x<1.4)$ where the minimum of $D_{i t}$ is roughly constant, and is within the range $(3-5) \times 10^{11} \mathrm{~cm}^{-2} \mathrm{eV}^{-1}$. These are among the better values reported for this device [5]. When the $\mathrm{SiN}_{x}: \mathrm{H}$ becomes N-rich $(x>1.4)$, the minimum of $D_{i t}$ increases sharply. We have found a close relation between the presence/absence of traps at the interface and the presence/absence of $\mathrm{N}-\mathrm{H}$ bonds in the $\mathrm{SiN}_{x}: \mathrm{H}$. In fact in figure 3 we present the minimum of $D_{i t}$ and the concentration of $\mathrm{N}-\mathrm{H}$ bonds at the insulator as a function of $x$. Notice that the dependence on the film composition of both the minimum of $D_{i t}$ and the concentration of $\mathrm{N}-\mathrm{H}$ bonds is quite similar over the entire range of compositions analysed. A possible explanation for these results may be related to the role that $\mathrm{N}-\mathrm{H}$ bonds play at the $\mathrm{SiN}_{x}: \mathrm{H} / \mathrm{Si}$ interface. On interfaces of the type (oxidenitride-oxide)/Si, it was recently reported that $\mathrm{N}-\mathrm{H}$ bonds located near to $\mathrm{Si}-\mathrm{H}$ surface terminated bonds, i.e. bonds of the type $\mathrm{H}-\mathrm{Si} \equiv \mathrm{Si}_{3}$, act as a precursor site to defect generation $[10,11]$. Actually, the $\mathrm{N}-\mathrm{H}$ bond captures the $\mathrm{H}$ from the $\mathrm{Si}-\mathrm{H}$, via the trapping of a hole, and this gives rise to the presence of an $\mathrm{N}-\mathrm{H}_{2}$ overcoordinated bond and a surface dangling bond, i.e. a $\bullet \mathrm{Si} \equiv \mathrm{Si}_{3}$ dangling bond. These are the source of $D_{i t}$. Whenever the concentration of N-H rises, in N-rich films, the minimum of $D_{i t}$ also rises, as figure 3 shows. A similar dependence between the minimum of $D_{i t}$ and the concentration of $\mathrm{N}-\mathrm{H}$ has already been found by Ma et al [12] on (oxide-nitride-oxide)/Si devices. The results of this paper indicate that the presence of $\mathrm{N}-\mathrm{H}$ bonds in $\mathrm{SiN}_{x}: \mathrm{H}$ films have a negative influence on the electrical characteristics of $\mathrm{SiN}_{x}: \mathrm{H} / \mathrm{Si}$ devices. A more detailed characterization of these structures using deep level transient spectroscopy is now in progress and its results will be published elsewhere [13].

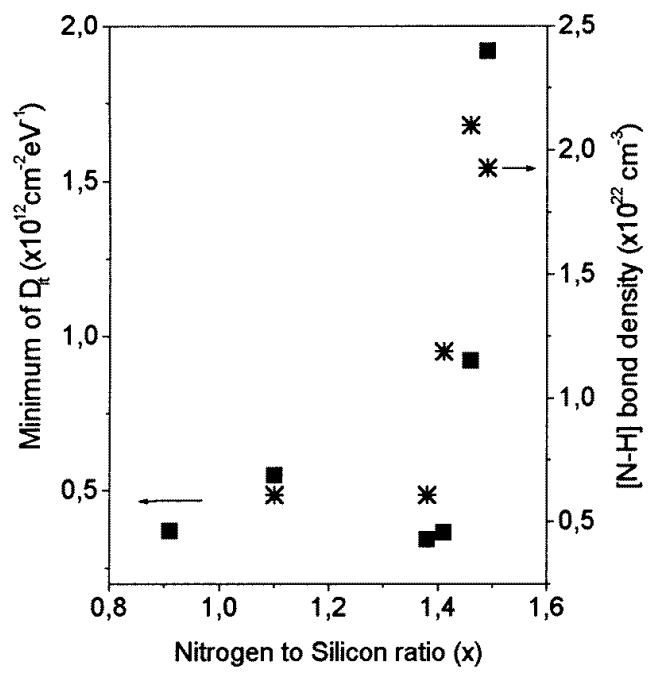

Figure 3. Minimum of the interface trap density ( $\mathbf{\square})$ and $\mathrm{N}-\mathrm{H}$ bond concentration at $\mathrm{SiN}_{x}: \mathrm{H}(*)$ for the $\mathrm{SiN}_{x}: \mathrm{H} / \mathrm{Si}$ device, as a function of the composition of the film, $x$.

In relation to the devices based on InP, we show in figure 4 the interface trap distribution within the forbidden gap for a device where the insulator was deposited at $R=9$. This ratio was found to be the optimum for obtaining devices with good electrical characteristics. At this value of $R$, the film composition was $x=1.49$. In all the structures based on InP the minimum of the interface trap density appears at $0.42 \mathrm{eV}$ above the midgap $(0.25 \mathrm{eV}$ below the conduction band). This location within the forbidden gap is similar to the data previously reported by other authors [14]. On these capacitors, the range of energies where the trap density is low was smaller than in Si based devices, which is probably due to a more defective interface. The devices in which the composition of the insulator was $x<1.49$ exhibited a trap distribution similar to that of figure 4, though the minimum of $D_{i t}$ was dependent on film composition. This will be discussed in the next paragraph.

From the results of figure 2, it can be deduced that the relation between the minimum of $D_{i t}$ and the film composition for the devices based on InP is completely different from those based on $\mathrm{Si}$. Now, the relation between the minimum of $D_{i t}$ and the film composition, $x$, can be explained tentatively as follows: when an insulator is plasma deposited on InP, the semiconductor surface loses the group $\mathrm{V}$ element (phosphorus) [6]. As a consequence, the surface becomes a zone with phosphorus vacancies, $\mathrm{V}_{\mathrm{P}}$, and in general atomically disordered [14]. The results of figure 2 indicate that, as the film composition changes from Si-rich $(x<1)$ to $\mathrm{N}$-rich $(x>1.33)$, the minimum of $D_{i t}$ changes as well. The lowest value of $D_{i t}$ is obtained on the device where the insulator has the highest value of $x(x=1.49)$. This suggests that the excess nitrogen in plasma-deposited $\mathrm{SiN}_{x}: \mathrm{H}$ films may passivate the InP surface. When the $\mathrm{SiN}_{x}: \mathrm{H}$ are plasma deposited, the nitrogen atoms get to the InP surface with sufficient energy to move through the first atomic layers of the surface and reach $P$ vacancies, $V_{P}$. Once at the $V_{P}$, 


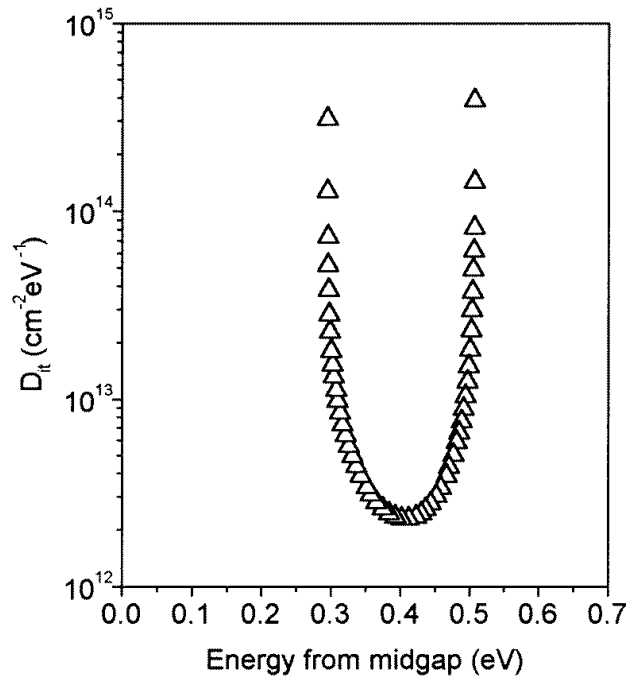

Figure 4. Distribution of interface trap density versus energy plotted relative to the midgap, for the $\mathrm{SiN}_{x}: \mathrm{H} / \mathrm{lnP}$ device. Results are for optimum deposition conditions of the insulator.

nitrogen atoms may fill them, giving rise to the appearance of substitutionals of the type $\mathrm{N}_{\mathrm{Vp}}$. These $\mathrm{N}_{\mathrm{Vp}}$ act in a similar way to sulphur in InP surfaces passivated with this element $[4,15]$. The minimum of $D_{i t}$ that we obtain under the better conditions for the deposition of $\mathrm{SiN}_{x}: \mathrm{H}$ is $2 \times 10^{12} \mathrm{~cm}^{-2} \mathrm{eV}^{-1}$ (figure 4). This value is almost the same as those reported on devices where the InP was passivated using different procedures $[4,15,16]$. This result seems to be highly promising, since it could be possible to use ECR plasma methods to deposit insulators that passivate the surface of III-V semiconductors effectively without the use of additional passivation procedures.

\section{Conclusions}

We have obtained MIS capacitors with two different semiconductors, $\mathrm{Si}$ and $\mathrm{InP}$, by depositing $\mathrm{SiN}_{x}: \mathrm{H}$ films at low temperature $\left(200^{\circ} \mathrm{C}\right)$ with the ECR plasma method. On the devices based on $\mathrm{Si}$, the minimum of the interface trap density, $D_{i t}$, was roughly constant for insulator compositions $x<1.4$. When the composition was $x>1.4$, i.e. when the $\mathrm{SiN}_{x}: \mathrm{H}$ becomes $\mathrm{N}$ rich, we found a clear relation between the number of interface traps and the amount of hydrogen bonded to nitrogen in the insulator. These bonds, located at the interface with $\mathrm{Si}$, induce the appearance of $\mathrm{Si}$ dangling bonds coming from $\mathrm{H}-\mathrm{Si} \equiv \mathrm{Si}_{3}$ bonds that lose the $\mathrm{H}$ and give rise to the appearance of an $\mathrm{N}-\mathrm{H}_{2}$ overcoordinated bond and a unpaired $\bullet \mathrm{Si} \equiv \mathrm{Si}_{3}$ dangling bond that acts as a precursor site to defect generation.

On the devices based on InP, the excess of nitrogen in $\mathrm{SiN}_{x}: \mathrm{H}$ films that are $\mathrm{N}$-rich seems to effectively passivate the InP surface via the formation of substitutional $\mathrm{N}_{\mathrm{Vp}}$. The minimum of $D_{i t}$ obtained in these structures $\left(2 \times 10^{12} \mathrm{~cm}^{-2} \mathrm{eV}^{-1}\right)$ indicates that these $\mathrm{N}_{\mathrm{Vp}}$ effectively passivate the surface. This result opens up the possibility of attaining good quality interfaces with III-V semiconductors by the deposition of $\mathrm{SiN}_{x}: \mathrm{H}$ films with excess nitrogen and without the use of specific passivation techniques.

\section{Acknowledgments}

The authors would like to thank E Iborra for the facilities for the infrared characterization of films. This research was partially supported by the Spanish CYCIT under grant No TIC 93/0175.

\section{References}

[1] Tao M, Park D G, Mohammed S N, Li D, Botchkarev A E and Morkoc H 1996 Phil. Mag. B 73723

[2] Garcia S, Martin J M, Mártil I, Fernandez M and Gonzalez Diaz G 1996 Phil. Mag. B 73487

[3] Park D G, Tao M, Li D, Botchkarev A E, Fan Z, Wang Z, Mohammed S N, Rockett A, Abelson J R, Morkoc H, Heyd A R and Alterovitz S A 1996 J. Vac. Sci. Technol. B 142674

[4] Kapila A, Si X and Malhotra V 1993 Appl. Phys. Lett. 62 2259

[5] Sitbon S, Hugon M C, Agius B, Abel F, Courant J L and Puesh M 1995 J. Vac. Sci. Technol. A 132900

[6] Hashizume T, Hasegawa H, Riemenschneider R and Hartnagel H L 1994 Japan. J. Appl. Phys. 33727

[7] Parmiter P J M and Swanson J G 1996 J. Electron. Mater. 251506

[8] Lanford W A and Rand M J 1978 J. Appl. Phys. 492473

[9] Nicollian E H and Brews J R 1982 MOS Physics and Technology (New York: Wiley)

[10] Ying Z, Lucovsky G and Whitten J L 1995 J. Vac. Sci. Technol. B 131613

[11] Lucovsky G, Ying Z and Lee D R 1996 J. Vac. Sci. Technol. B 142832

[12] Ma Y, Yasuda T and Lucovsky G 1994 Appl. Phys. Lett. 642226

[13] Garcia S, Mártil I, Gonzalez Diaz G, Castan E, Dueñas S and Fernandez M J. Appl. Phys. at press

[14] Hasegawa H, Akazawa M, Ishii H and Matsuzaki K 1989 J. Vac. Sci. Technol. B 7870

[15] Sundaraman C S, Milhelich P, Masut R A and Curri J F 1994 Appl. Phys. Lett. 642279

[16] Landheer D, Lu Z H, Baribeau J M, Huang L J and Lau W M 1994 J. Electron. Mater. 23943 